\title{
Influence of layer microstructure on the double nucleation process in $\mathrm{Cu} / \mathrm{Mg}$ multilayers
}

\author{
M. Gonzalez-Silveira, J. Rodriguez-Viejo, ${ }^{\text {a) }}$ and G. Garcia \\ Grup de Nanomaterials i Microsistemes, Unitat de Física de Materials I, Departament de Física, \\ Universitat Autònoma de Barcelona, 08193 Bellaterra, Spain \\ F. Pi \\ Grup d'òptica, Departament de Física, Universitat Autònoma de Barcelona, 08193 Bellaterra, Spain \\ F. J. Ager \\ Centro Nacional de Aceleradores, Avenida Thomas A. Edison, 41092 Sevilla, Spain
}

J. L. Lábár, A. Barna, M. Menyhárd, and L. Kótis

Research Institute for Technical Physics and Materials Science, P.O. Box 49, Budapest 114 H-1525, Hungary

(Received 25 May 2006; accepted 21 September 2006; published online 11 December 2006)

\begin{abstract}
We have investigated by differential scanning calorimetry the thermal evolution of $\mathrm{Cu} / \mathrm{Mg}$ multilayers with different modulation lengths, ranging from 7/28 to 30/120 nm. The $\mathrm{Cu}$ and $\mathrm{Mg}$ layers were grown by sequential evaporation in an electron beam deposition system. The phase identification and layer microstructure were determined by cross-section transmission electron microscopy, Rutherford backscattering, and scanning electron microscopy with focused ion beam for sample preparation. Upon heating, the intermetallic $\mathrm{CuMg}_{2}$ forms at the interfaces until coalescence is reached and thickens through a diffusion-limited process. Cross-section transmission electron microscopy observations show a distinct microstructure at the top and bottom of the as-prepared $\mathrm{Mg}$ layers, while no significant differences were seen in the $\mathrm{Cu}$ layers. We show that this effect is responsible for the observed asymmetry in the nucleation process between the $\mathrm{Cu}$ on $\mathrm{Mg}$ and the $\mathrm{Mg}$ on $\mathrm{Cu}$ interfaces. By modeling the calorimetric data we determine the role of both interfaces in the nucleation and lateral growth stages. We also show that vertical growth proceeds by grain development of the product phase, increasing significantly the roughness of the interfaces.
\end{abstract}

(C) 2006 American Institute of Physics. [DOI: 10.1063/1.2398001]

\section{INTRODUCTION}

When a reaction occurs in a thin film system, the early stages of reaction between vicinal layers might be clearly different from what happens in equivalent bulk samples, and even metastable phases may be formed. Multilayers are ideal configurations to investigate the role of the interfaces on the nucleation kinetics ${ }^{1,2}$ and phase formation sequence, ${ }^{3-5}$ since they provide a large number of reacting interfaces. To achieve a good comprehension of the high reactivity occurring in those multistructures when submitted to different treatments, either mechanical essays or thermal annealings, a deep microstructural characterization becomes necessary. In the particular case of the thermal evolution of a sample, differential scanning calorimetry (DSC) is a powerful technique that provides thermodynamic and kinetic informations related to the nucleation and growth processes of the new phases $^{3,5-8}$ and, when combined with transmission electron microscopy (TEM) for microstructure identification, it can provide detailed information on the interfacial activity during thin film reactions. ${ }^{1,3,9-11}$

Several studies have previously analyzed the $\mathrm{Cu}-\mathrm{Mg}$ multilayer system upon heat treatments. Li et al. ${ }^{12}$ and Hong

${ }^{a)}$ Electronic mail: javirod@vega.uab.es and d'Heurle ${ }^{13}$ demonstrated that the first phase to form at the interfaces during heat treatments is the $\mathrm{CuMg}_{2}$ intermetallic for any atomic concentration ratio, which corresponds to the phase with the higher content of the lower melting point element. The same rule applies for other diffusion couples such as $\mathrm{Cu}-\mathrm{Ti}, \mathrm{Cu}-\mathrm{Zr}$, or $\mathrm{Cu}-\mathrm{Sb}$. Once the intermetallic has formed, the diffusion studies performed by Hong and d'Heurle demonstrated that $\mathrm{Cu}$ diffuses faster than $\mathrm{Mg}$ through the $\mathrm{CuMg}_{2}$ phase, in contradiction with the hypothesis that the predominant diffusion species is the majority element of the compound. On the other hand, Arcot et al. ${ }^{14}$ studied the $\mathrm{Cu}-\mathrm{Mg}$ multilayer system, characterizing films of different modulation lengths by calorimetry. They reported that the growth of the intermetallic $\mathrm{CuMg}_{2}$ phase takes place in two well separated stages: nucleation and lateral growth of the intermetallic along the interface until coalescence is complete, followed by a diffusion limited vertical growth of the same intermetallic phase. A similar behavior has been observed in other multilayer systems such as $\mathrm{Al} / \mathrm{Ni},{ }^{11,15}$ $\mathrm{Al} / \mathrm{Nb},{ }^{9,16,17} \mathrm{Al} / \mathrm{Ag},{ }^{18} \mathrm{Al} / \mathrm{Co},{ }^{3} \mathrm{Ni} / \mathrm{Si}^{7,}{ }^{76} \mathrm{~V} / \mathrm{Si}^{19}{ }^{19}$ or $\mathrm{Cu} / \mathrm{Sn}^{20}$ Coffey et al. ${ }^{16}$ developed a kinetic model that incorporates the two stage model and allowed the simulation of the corresponding calorimetric traces. This simplified model has been applied to several diffusion couples. ${ }^{11,19,21}$ However, despite a substantial progress in the understanding of thin film reactions and reactive phase formation, the compre- 
hension of the microstructural influence on the early nucleation and growth mechanisms is still incomplete. Prior works $^{14,22,23}$ have unambiguously shown that the formation of the first nuclei of the product phase is preceded by a mixing process of the initial components. Once the critical concentration gradient is exceeded nucleation is possible at specific points of the interface, depending on the energy barriers for nucleation. Different possibilities arise: The product phase can nucleate at the $A / B$ interface, ${ }^{24}$ heterogeneously at triple grain boundaries ${ }^{9,16,25}$ or inside grain boundaries. ${ }^{26}$ As the density and type of grain boundaries depend on the specific microstructure at the interface, it is expected that the growth mode of the layer may be a key point for understanding nucleation. Several authors have previously addressed the influence of microstructure on nucleation. A work in this direction was carried out by Lever et al., ${ }^{27}$ who showed the anomalous growth of $\mathrm{HfAl}_{3}$ from $\mathrm{Hf}$ and $\mathrm{Al}$ films and related it to the asymmetry in both interfaces, $\mathrm{Hf}$ on $\mathrm{Al}$ and $\mathrm{Al}$ on Hf. Other authors ${ }^{9-11,28}$ have observed a correlation between the nucleation and growth temperature and the modulation thickness of the bilayers. Once the product phase has nucleated, new fast diffusion paths open along the phase boundary between the new grains and the surrounding area, providing rapid transport for the different species. ${ }^{22,29}$ This leads to a very fast lateral growth along the interface until coalescence of the grains takes place. Although critical radii are only a few nanometers, DSC data and microscopy observations typically show that the first stage of the reaction consists in the formation of a $10 \mathrm{~nm}$ thick product layer. In some cases, the intermetallic layer penetrates into the grain boundaries due to fast transport even before nucleation starts. ${ }^{9}$

In a former work, we have shown the existence of a differentiated nucleation process depending on the type of interface, $\mathrm{Cu}$ on $\mathrm{Mg}(\mathrm{Cu} / \mathrm{Mg})$ or $\mathrm{Mg}$ on $\mathrm{Cu}(\mathrm{Mg} / \mathrm{Cu}){ }^{30}$ However, the reason for such behavior was unclear. The difficulty in performing high-resolution transmission electron microscopy (HRTEM) on Mg thin films precluded the identification of a correlation between the microstructure and intermetallic formation. In this paper we present calorimetric data on a set of multilayers with different modulation thicknesses, along with HRTEM and Rutherford backscattering spectrometry (RBS) measurements. Based on these observations we provide a plausible explanation for the unexpected nucleation behavior at both interfaces.

\section{EXPERIMENT}

$\mathrm{Cu} / \mathrm{Mg}$ multilayer samples with different modulation lengths were deposited by alternate e-beam deposition (EBD) of $\mathrm{Mg}$ and $\mathrm{Cu}$ layers. Further details of the deposition conditions are given elsewhere. ${ }^{31}$ The six different samples under study are identified by the thickness relation between the $\mathrm{Cu} / \mathrm{Mg}$ layers expressed in nanometers: (a) 10/100, (b) 30/120, (c) 20/80, (d) 15/60, (e) 7/28, and (f) 10/20. The total thickness of the samples never exceeded $1 \mu \mathrm{m}$. In all cases the deposition started and finished with a $\mathrm{Cu}$ layer of $20 \mathrm{~nm}$ in order to prevent the oxidation of the $\mathrm{Mg}$ layers. Without considering the extra layers, samples 30/120, $20 / 80,15 / 60$, and $7 / 28$ have an atomic concentration ratio
TABLE I. Individual layer thickness for the different deposited samples. The molar concentration ratio has been calculated without taking into account the extra $\mathrm{Cu}$ layer.

\begin{tabular}{cccc}
\hline \hline Sample & $d_{\mathrm{Cu}}(\mathrm{nm})$ & $d_{\mathrm{Mg}}(\mathrm{nm})$ & Molar ratio \\
\hline $10 / 100$ & 10 & 100 & $1 \mathrm{Cu}: 5 \mathrm{Mg}$ \\
$30 / 120$ & 30 & 120 & $1 \mathrm{Cu}: 2 \mathrm{Mg}$ \\
$20 / 80$ & 20 & 80 & $1 \mathrm{Cu}: 2 \mathrm{Mg}$ \\
$15 / 60$ & 15 & 60 & $1 \mathrm{Cu}: 2 \mathrm{Mg}$ \\
$7 / 28$ & 7 & 28 & $1 \mathrm{Cu}: 2 \mathrm{Mg}$ \\
$10 / 20$ & 10 & 20 & $1 \mathrm{Cu}: 1 \mathrm{Mg}$ \\
\hline \hline
\end{tabular}

of $1 \mathrm{Cu}: 2 \mathrm{Mg}$, while in the case of sample $10 / 100$ the relation is $1 \mathrm{Cu}: 5 \mathrm{Mg}$ and $1 \mathrm{Cu}: 1 \mathrm{Mg}$ for sample $10 / 20$ (see Table I).

Thermal analysis was performed in a powercompensated differential scanning calorimeter DSC-7 from Perkin Elmer with a power resolution of $4 \mu \mathrm{W}$. Films were heated in a flowing Ar atmosphere at 10,20 , and $40{ }^{\circ} \mathrm{C} / \mathrm{min}$. In order to improve the signal to noise ratio, samples used for calorimetric measurements were deposited onto Si wafers coated with a photoresist layer and removed from the substrate by an acetone bath, resulting on free-standing samples. The calorimetric base line was obtained by a repetition of the heat treatment and was subtracted afterwards from the original curve. Samples deposited directly on Si were used for TEM and scanning electron microscopy (SEM) analyses. Specific heat treatments were conducted inside the DSC furnace, which was previously recalibrated for non-freestanding samples. A kinetic model, explained in detail in Rodriguez-Viejo et al., ${ }^{31}$ has been used to reproduce the calorimetric curves corresponding to the formation of the intermetallic $\mathrm{CuMg}_{2}$ phase as divided in two differentiate stages: lateral and vertical growths. In order to reproduce the different behaviors at both interfaces, the first transformation stage is treated separately for each kind of interface, $\mathrm{Cu}$ over $\mathrm{Mg}(\mathrm{Cu} / \mathrm{Mg})$ and $\mathrm{Mg}$ over $\mathrm{Cu}(\mathrm{Mg} / \mathrm{Cu})$. Information regarding kinetic parameters such as nucleation and growth rates as well as nuclei density and initial size can be extracted from the fittings.

The analysis of the layer thickness distribution was performed by $\mathrm{RBS}$, with a $\mathrm{He}^{++}$beam of $1.986 \mathrm{MeV}$ collimated at $1 \times 1 \mathrm{~mm}^{2}$. The spectra were fitted with the SIMNRA code ${ }^{32}$ to obtain the layer thickness information. Auger electron spectroscopy (AES) with spectrometer of DESA100, coupled with an $\mathrm{Ar}^{+}$ion milling at $1 \mathrm{keV}$ for depth profiling, was used to measure the degree of interdiffusion at the interfaces, as well as the presence of oxygen or other impurities at the interface. The samples were also investigated using an analytical transmission electron microscope JEOL 3010 at $300 \mathrm{keV}$. Specific polishing and thinning procedures using lubricants without water were employed to minimize sample oxidation. Final thinning to the electron transparency was achieved by milling from both sides using a low energy ion mill machine IV3 II/I, from Technoorg at $250 \mathrm{eV}$. The samples were cooled during thinning. Electron energy loss spectroscopy and elemental mapping were performed with a GATAN GIF Tridiem postcolumn filter. An integrated scanning electron microscope with a focused ion beam (FIB), Strata DB235, was used to prepare in situ cross-section 


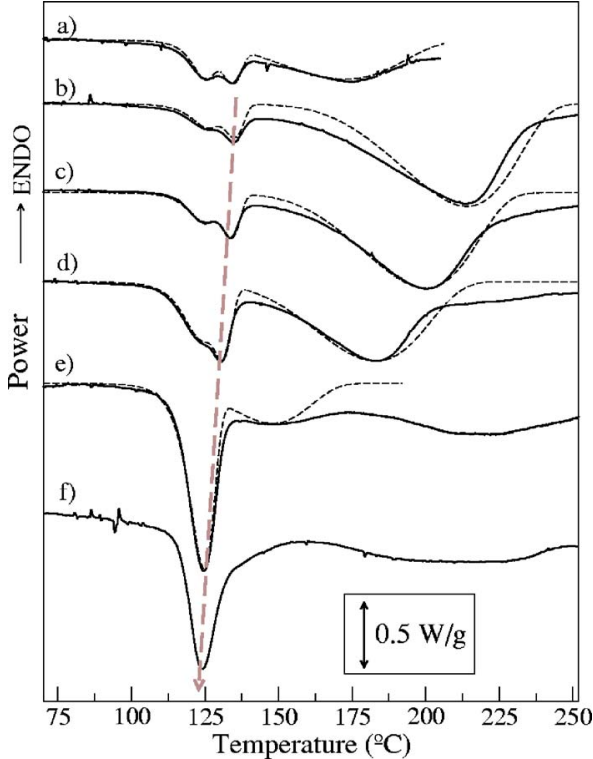

FIG. 1. Solid lines correspond to DSC continuous heat treatment curves obtained at $10^{\circ} \mathrm{C} / \mathrm{min}$ from samples $10 / 100$ (a), 30/120 (b), 20/80 (c), $15 / 60$ (d), 7/28 (e), and 10/20 (f). Dash lines correspond to the modeling of the calorimetric curves. Curves (b)-(f) are arranged in decreasing order of $\mathrm{Mg}$ layer thickness. The discontinuous arrow is a guide to the eye to follow the evolution of the second calorimetric peak as a function of the Mg layer thickness.

specimens for the analysis of the multilayer evolution after different thermal treatments.

\section{RESULTS}

\section{A. Calorimetric analysis}

Figure 1 shows the calorimetric curves obtained for different multilayer samples under continuous heat treatment at $10{ }^{\circ} \mathrm{C} / \mathrm{min}$. In all cases a succession of exothermic reactions was observed. For samples with thicker layers (10/100, $30 / 120,20 / 80$, and $15 / 60$ ), three peaks can be clearly distinguished, the first two overlapped and the third one at higher temperatures. As has already been demonstrated for a $20 / 80$ sample, $^{30,31}$ the first two peaks correspond to the nucleation and lateral growth of the $\mathrm{CuMg}_{2}$ intermetallic phase at each type of interface. The transformation at $\mathrm{Mg} / \mathrm{Cu}$ interfaces is associated to the lower temperature calorimetric peak, while the second peak corresponds to the reactions at $\mathrm{Cu} / \mathrm{Mg}$ interfaces. The third exothermic peak is the result of the vertical growth of the same intermetallic phase. In the case of thinner layers, samples $7 / 28$ and 10/20, only one exothermic peak can be clearly identified at low temperature. In these samples, the asymmetry of that peak at the high temperature end is due to the superposition of the vertical growth with the lateral growth stage because of the smaller diffusion path through the $\mathrm{CuMg}_{2}$ product phase. The broad peak occurring around $200-250{ }^{\circ} \mathrm{C}$ is associated with the formation of the intermetallic $\mathrm{Cu}_{2} \mathrm{Mg}$. This phase forms when some $\mathrm{Cu}$ remains after the transformation into $\mathrm{CuMg}_{2}$ is completed. ${ }^{14}$ While in the case of sample 10/20 excess $\mathrm{Cu}$ comes from the original atomic concentration ratio (1Cu: $1 \mathrm{Mg}$ ); in the case of sample $7 / 28$, the protective layer provides enough excess $\mathrm{Cu}$ to form the new intermetallic phase. The coalescence thickness of the intermetallic phase after the first stage can be deduced from the disappearance of the vertical growth peak. From Fig. 1 this period should be around $20-25 \mathrm{~nm}$, giving a coalescence thickness between 10 and $12 \mathrm{~nm}$.

As shown in Fig. 1 by a discontinuous arrow, the evolution of the nucleation and lateral growth stages strongly depends on layer thickness. While the transformation at the $\mathrm{Mg} / \mathrm{Cu}$ interfaces always occurs at the same temperature (first calorimetric peak), the $\mathrm{Cu} / \mathrm{Mg}$ interface reacts at different temperatures depending on the thickness of the $\mathrm{Mg}$ layer. The thicker the $\mathrm{Mg}$ layer, the higher the temperature at which the reaction takes place at this interface. No dependence with $\mathrm{Cu}$ layer thickness has been observed, as can be deduced from sample 10/100, which behaves similarly than sample 30/120 during the first transformation stage even when the $\mathrm{Cu}$ layer is three times thinner.

A reliable kinetic information of each sample is obtained from the modeling of the calorimetric traces at different heating rates, namely 10,20 , and $40{ }^{\circ} \mathrm{C} / \mathrm{min}$. The model is based on the previous work by Coffey et al., ${ }^{16}$ although it contains significant differences to improve the fitting of the calorimetric traces at constant heating rate. The model has been described in detail elsewhere. ${ }^{30,31}$ Briefly, the growth of the intermetallic phase is described using nuclei with cylindrical shape and a temperature dependent nucleation rate. The lateral growth of the grains is taken to be interface controlled whereas the vertical growth is driven by diffusion through the $\mathrm{CuMg}_{2}$ intermetallic layer. The gradual termination of the vertical growth peak is reproduced incorporating into the growth rate a $(1-x)$ factor which indicates a soft-diffusion control. This behavior may be related to the thickness inhomogeneity of the product phase during the vertical growth stage (see Sec. IV B). The main parameters obtained from the model, the preexponential factor and activation energies of the nucleation frequency and the lateral growth rate, are shown in Table II for the different samples. The activation energies extracted from the calorimetric trace fitting at the different heating rates are comparable to those calculated by the Kissinger method. ${ }^{33}$ The total number of nuclei per unit area associated to each interface is also shown in Table II. This value is calculated by integrating the temperature dependent nucleation rate along the specific temperature interval for each peak. The nuclei density associated to the $\mathrm{Mg}$ on the $\mathrm{Cu}$ interface is always higher, by about an order of magnitude, than that obtained for the $\mathrm{Cu}$ on the $\mathrm{Mg}$ interface except for the $7 / 28$ sample. The superposition of both peaks for the thinner multilayer, $7 / 28$, reflects a similar behavior for both interfaces. Since no vertical growth takes place during the nucleation and lateral growth stages, the height of the initial nuclei at interface $i, l_{i}$, equals the thickness of the $\mathrm{CuMg}_{2}$ layer. As a general trend, the thickness of the intermetallic layer is consistently thinner at the $\mathrm{Mg} / \mathrm{Cu}$ interfaces, with an average value of $6 \mathrm{~nm}$, than that of the $\mathrm{Cu} / \mathrm{Mg}$ interface, with a value of $9.3 \mathrm{~nm}$.

\section{B. Composition analysis}

Figure 2 shows the RBS measurements for sample $20 / 80$ as prepared and heat treated until completing the lat- 
TABLE II. Values used for the modeling of the calorimetric signal. (Ref. 30 and 31). $E_{\text {ap }}$ has been calculated from $E_{U}$ and $E_{I}$ using $E_{\text {ap }}=\left(E_{I}+3 E_{U}\right) / 4$. $E_{\text {kiss }, i}$ has been calculated by the Kissinger method (Ref. 33). The calculus of the nuclei formed at the end of the transformation $n_{i}$ has been performed by the integration of the nucleation rate curve as a function of time.

\begin{tabular}{llcccccccc}
\hline \hline & & $\begin{array}{c}I_{o, i} \\
\left(\mathrm{~cm}^{-2} \mathrm{~s}^{-1}\right)\end{array}$ & $\begin{array}{c}E_{I, i} \\
(\mathrm{eV} / \text { at. })\end{array}$ & $\begin{array}{c}U_{o, i} \\
(\mathrm{~cm} / \mathrm{s})\end{array}$ & $\begin{array}{c}E_{U, i} \\
(\mathrm{eV} / \mathrm{at} .)\end{array}$ & $\begin{array}{c}E_{\text {ap }, i} \\
(\mathrm{eV} / \text { at. })\end{array}$ & $\begin{array}{c}E_{\text {kiss }, i} \\
(\mathrm{eV} / \mathrm{at} .)\end{array}$ & $\begin{array}{c}l_{i} \\
(\mathrm{~nm})\end{array}$ & $\begin{array}{c}n_{i} \\
\left(\mathrm{~cm}^{-2}\right)\end{array}$ \\
\hline $10 / 100$ & $\mathrm{Mg} / \mathrm{Cu}$ & $6.1 \times 10^{30}$ & 1.54 & $1.5 \times 10^{9}$ & 1.38 & 137.0 & $1.39 \pm 0.01$ & 5.6 & $6.0 \times 10^{12}$ \\
& $\mathrm{Cu} / \mathrm{Mg}$ & $7.0 \times 10^{28}$ & 1.45 & $8.0 \times 10^{8}$ & 1.38 & 134.8 & $1.35 \pm 0.06$ & 6.5 & $3.2 \times 10^{12}$ \\
$30 / 120$ & $\mathrm{Mg} / \mathrm{Cu}$ & $1.5 \times 10^{31}$ & 1.54 & $8.0 \times 10^{8}$ & 1.38 & 137.0 & $1.35 \pm 0.12$ & 6.2 & $1.2 \times 10^{13}$ \\
& $\mathrm{Cu} / \mathrm{Mg}$ & $1.5 \times 10^{28}$ & 1.45 & $1.6 \times 10^{9}$ & 1.38 & 134.8 & $1.34 \pm 0.06$ & 9.4 & $7.6 \times 10^{11}$ \\
$20 / 80$ & $\mathrm{Mg} / \mathrm{Cu}$ & $1.7 \times 10^{31}$ & 1.54 & $9.3 \times 10^{8}$ & 1.38 & 137.0 & $1.32 \pm 0.04$ & 5.2 & $1.3 \times 10^{13}$ \\
& $\mathrm{Cu} / \mathrm{Mg}$ & $1.7 \times 10^{28}$ & 1.45 & $1.8 \times 10^{9}$ & 1.38 & 134.8 & $1.31 \pm 0.01$ & 8.8 & $7.7 \times 10^{11}$ \\
$15 / 60$ & $\mathrm{Mg} / \mathrm{Cu}$ & $2.1 \times 10^{31}$ & 1.54 & $1.1 \times 10^{9}$ & 1.38 & 137.0 & $1.41 \pm 0.19$ & 7.0 & $1.1 \times 10^{13}$ \\
& $\mathrm{Cu} / \mathrm{Mg}$ & $3.0 \times 10^{28}$ & 1.45 & $2.0 \times 10^{9}$ & 1.38 & 134.8 & $1.27 \pm 0.01$ & 12.0 & $9.4 \times 10^{11}$ \\
$7 / 28$ & $\mathrm{Mg} / \mathrm{Cu}$ & $2.2 \times 10^{26}$ & 1.24 & $5.8 \times 10^{6}$ & 1.17 & 1.19 & $1.71 \pm 0.08$ & 9.5 & $1.7 \times 10^{12}$ \\
& $\mathrm{Cu} / \mathrm{Mg}$ & $2.2 \times 10^{26}$ & 1.24 & $5.8 \times 10^{6}$ & 1.17 & 1.19 & $1.71 \pm 0.08$ & 9.5 & $1.7 \times 10^{12}$ \\
\hline \hline
\end{tabular}

eral growth stage at both interfaces. In both cases, the peaks corresponding to all $\mathrm{Cu}$ and $\mathrm{Mg}$ layers can be observed, as well as the continuous maximum associated to the Si substrate. The average calculated thicknesses for the different layers are shown in Table III. All the values have been converted from surface atomic density to length units by dividing by the bulk density of the different elements $(\mathrm{Mg}$ : $1.738 \mathrm{~g} \mathrm{~cm}^{-3}$ and $\mathrm{Cu}: 8.920 \mathrm{~g} \mathrm{~cm}^{-3}$ ) to obtain an estimation of layer thicknesses. The obtained values for the as-prepared sample are smaller than the nominal values, though this could be an artifact of the calculation due to the fact that experimental densities of EBD films are usually smaller than theoretical ones. ${ }^{34}$ In the case of the heat-treated sample, the presence of the $\mathrm{CuMg}_{2}$ intermetallic layers at the interfaces was considered by the definition of a region formed by a combination of $\mathrm{Cu}$ and $\mathrm{Mg}$ atoms with a concentration ratio of $1 \mathrm{Cu}: 2 \mathrm{Mg}$. For the conversion to length units, the $\mathrm{CuMg}_{2}$ bulk density was used $\left(3.405 \mathrm{~g} \mathrm{~cm}^{-3}\right)$. The thicknesses for these intermetallic layers are shown in Table III in the columns labeled as $\mathrm{Cu} / \mathrm{Mg}$ and $\mathrm{Mg} / \mathrm{Cu}$ indicating the type of

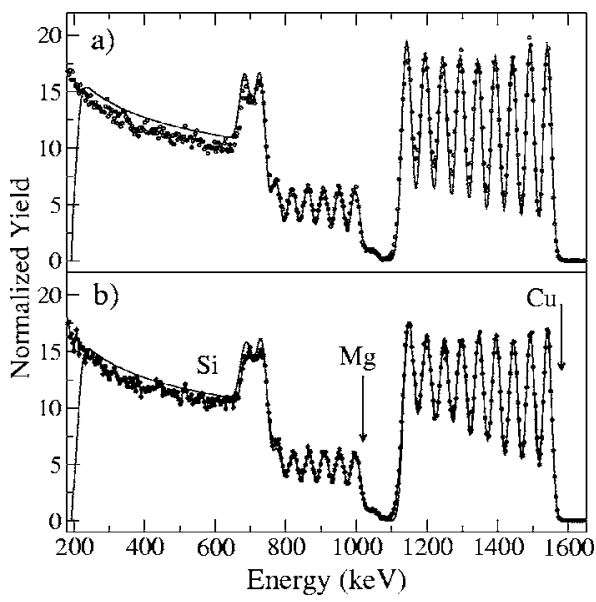

FIG. 2. RBS signal (dots) with the corresponding fittings (solid lines) of sample 20/80 (a) as prepared and (b) heat treated until completing the lateral growth stage at both interfaces. On graph (b), the energies corresponding to $\mathrm{Cu}, \mathrm{Mg}$, and $\mathrm{Si}$ are indicated. interface where the intermetallic layer is located. The intermetallic layer at $\mathrm{Cu} / \mathrm{Mg}$ interfaces is almost three times thicker than the equivalent layer at $\mathrm{Mg} / \mathrm{Cu}$ interfaces. The values obtained for the $\mathrm{Cu}$ and $\mathrm{Mg}$ layers are significantly smaller than those of the as-prepared samples indicating that the intermetallic has grown at the expense of the original layers.

Figure 3 shows the AES depth profile of an as-prepared 20/80 sample. The different $\mathrm{Cu}$ and $\mathrm{Mg}$ layers, as well as the presence of some oxygen at the top of the sample, can be clearly distinguished. The values obtained for $\mathrm{Cu}$ and $\mathrm{Mg}$ layer thicknesses are $22 \pm 3$ and $109 \pm 12 \mathrm{~nm}$, respectively. These values are higher than those calculated from RBS data. The relation between the thicknesses of both kinds of layers would represent a change in the atomic concentration ratio towards an excess of $\mathrm{Mg}$. A significant feature of the AES depth profile, highlighted in the detail graph of Fig. 3, is the different degree of mixing at both interfaces.

\section{Microstructure characterization}

Figure 4 shows a bright field cross-section transmission electron (XTEM) micrograph of an as-prepared 20/80 sample. The selected area diffraction analysis (SAED) (not shown) indicates that $\mathrm{Cu}$ films have a polycrystalline microstructure with no preferred orientation, while $\mathrm{Mg}$ films have a predominant columnar-type structure highly oriented with

TABLE III. Layer thicknesses obtained by the fitting of the RBS data from sample $20 / 80$ as prepared and heat treated until completing the lateral growth stage at both interfaces. The columns labeled as $\mathrm{Cu} / \mathrm{Mg}$ and $\mathrm{Mg} / \mathrm{Cu}$ correspond to the thickness of a layer composed by a mix of $\mathrm{Cu}$ and $\mathrm{Mg}$ with a concentration ratio of $1 \mathrm{Cu}: 2 \mathrm{Mg}$ at the corresponding interface.

\begin{tabular}{ccccc}
\hline \hline & \multicolumn{4}{c}{ Layer mean thickness (nm) } \\
\cline { 2 - 5 } Sample & $\mathrm{Cu}$ & $\mathrm{Cu} / \mathrm{Mg}$ & $\mathrm{Mg}$ & $\mathrm{Mg} / \mathrm{Cu}$ \\
\hline As prepared & $17.2 \pm 0.7$ & $\ldots$ & $78.5 \pm 1.1$ & $\ldots$ \\
Heat treated & $9.3 \pm 1.4$ & $29.2 \pm 5.5$ & $42.7 \pm 7.4$ & $9.8 \pm 1.6$ \\
\hline \hline
\end{tabular}



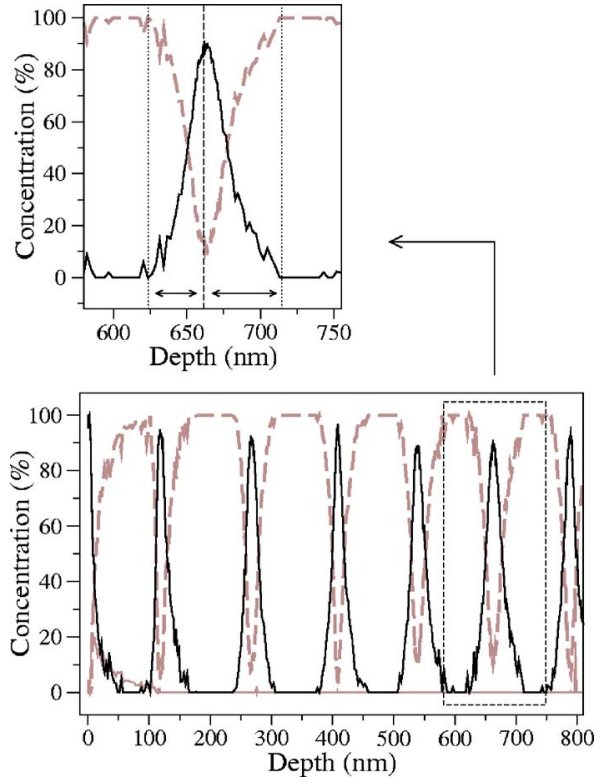

FIG. 3. AES depth profile of an as-prepared 20/80 sample. Concentrations of $\mathrm{Cu}$ (black solid line), $\mathrm{Mg}$ (gray dash line), and $\mathrm{O}$ (gray solid line) as a function of depth are represented. The top graph corresponds to a detail of a region of the complete composition profile.

the $c$ axis parallel to the growing direction and a partially equiaxed polycrystalline grain structure at the bottom of the layers extending as much as $1 / 4$ of the layer thickness [see Figs. 4(a) and 4(b)]. The elemental map taken with the $\mathrm{Cu} M$ edge (see Fig. 5) clearly shows the grain boundary structure with the presence of $y$-shaped bifurcations at regions below $1 / 4$ of the total layer thickness, corroborating the different grain size distributions at the two sides of the $\mathrm{Mg}$ layer. The columnar grains have an aspect ratio $d / h \approx 1$, where $d$ is the grain diameter and $h$ the height, which is around $3 / 4$ of the

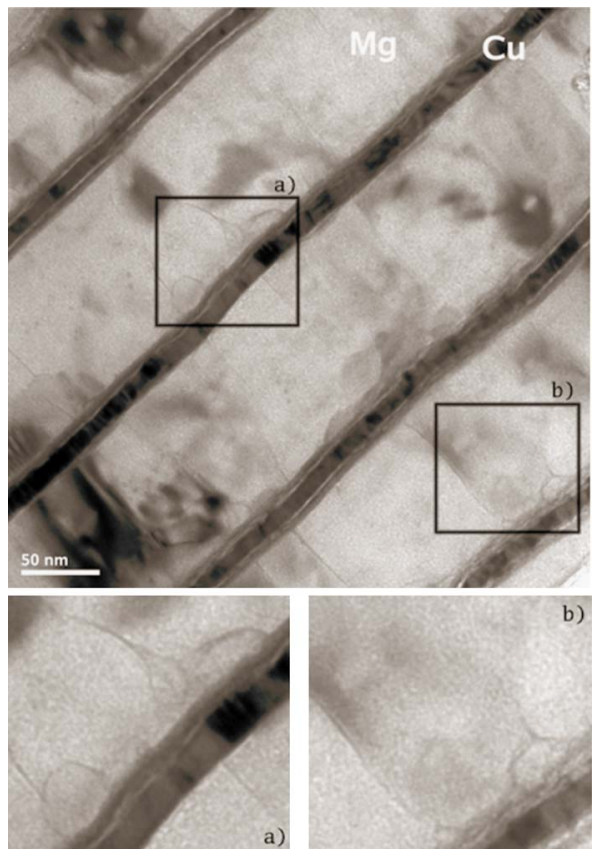

FIG. 4. Bright field XTEM picture of an as-prepared 20/80 sample. Dark fringes correspond to $\mathrm{Cu}$ layers. Bottom images correspond to enlargements of the indicated regions.

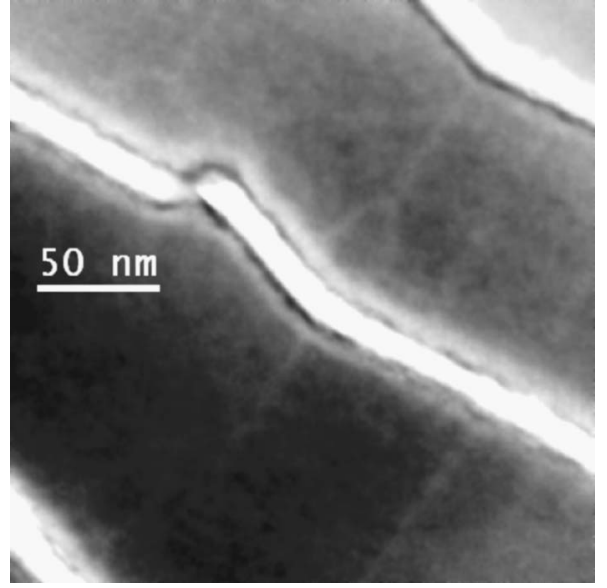

FIG. 5. The elemental map by $\mathrm{Cu} M$ edge of an as-prepared 20/80 sample. $\mathrm{Cu}$ can be identified in the image with white color and $\mathrm{Mg}$ with black, respectively. $\mathrm{y}$-shaped bifurcations of the $\mathrm{Mg}$ grain boundaries can be observed due to the diffusion of $\mathrm{Cu}$ through them.

layer thickness. An interdiffusion zone and dispersed $\mathrm{CuMg}_{2}$ nuclei can also be observed at the interfaces. Whether this nuclei are formed during XTEM preparation or during growth is still under investigation. An indication of grain boundary diffusion is seen in the electron-energy-loss spectroscopy (EELS) picture (Fig. 5).

Figure 6 shows a XTEM picture of sample 20/80 that has been previously treated until completing the lateral growth of the intermetallic at both interfaces. In the XTEM picture, the layers of intermetallic can be distinguished at both interfaces, showing different microstructures as a function of the interface. Taking into account that the rightbottom corner of the picture corresponds to the Si substrate, it is found that $\mathrm{CuMg}_{2}$ layers formed at the $\mathrm{Cu} / \mathrm{Mg}$ interfaces are thicker and more irregular than the ones formed at $\mathrm{Mg} / \mathrm{Cu}$ interfaces, in agreement with the results obtained by RBS and DSC measurements and modelings.

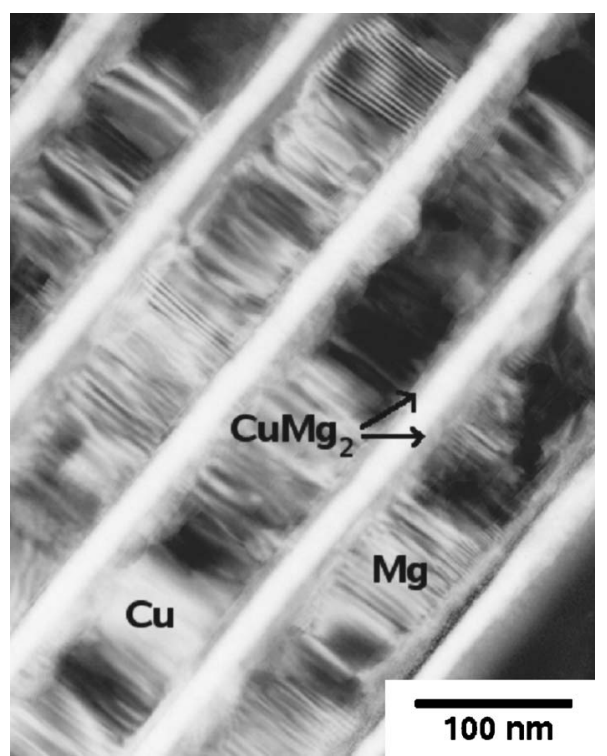

FIG. 6. XTEM image of a 20/80 sample that has been treated until completing the intermetallic lateral growth stage at both interfaces, $\mathrm{Mg} / \mathrm{Cu}$ and $\mathrm{Cu} / \mathrm{Mg}$. Dark fringes correspond to $\mathrm{Mg}$ layers while white ones correspond to $\mathrm{Cu}$ layers. The intermetallic phase can be distinguished at the interfaces. 


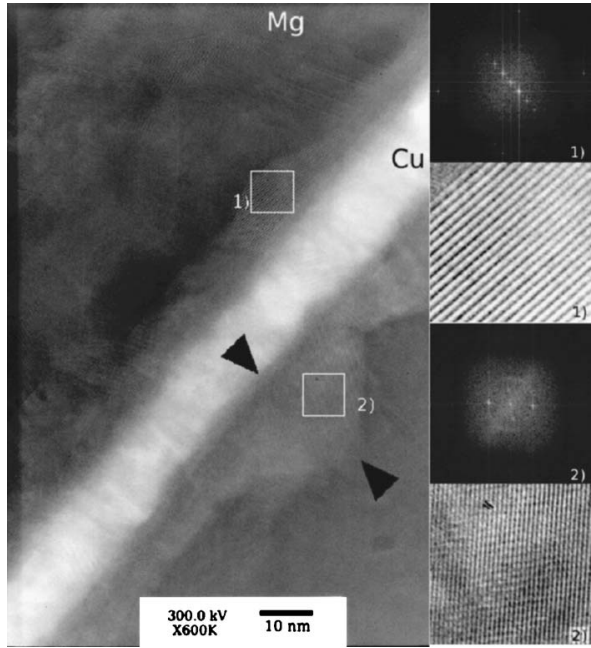

FIG. 7. HRTEM image of a 20/80 sample treated until completing the lateral growth of the intermetallic at both interfaces. Right side images correspond to enlarged details of the selected areas and the generated fast Fourier transform (FFT). In both cases, the areas have been identified with the $\mathrm{CuMg}_{2}$ phase. The arrows indicate a $\mathrm{CuMg}_{2}$ zone that enters into the $\mathrm{Mg}$ layer.

In order to study in more detail the intermetallic layer at both interfaces, an analysis by HRTEM was performed as shown in Fig. 7. The center of the image corresponds to a $\mathrm{Cu}$ layer sandwiched by the intermetallic layers that have been identified by the selected area diffraction analysis [see Figs. 7(a) and 7(b)]. While the $\mathrm{CuMg}_{2}$ layer at the $\mathrm{Mg} / \mathrm{Cu}$ interface is continuous with uniform thickness (approximately $10 \mathrm{~nm}$ ), the intermetallic at the $\mathrm{Cu} / \mathrm{Mg}$ interface presents an inhomogeneous thickness profile with some protuberances that enter into the $\mathrm{Mg}$ layer.

\section{Evolution of microstructure at higher temperature}

The evolution of the vertical growth stage as a function of temperature was analyzed by SEM. Figure 8 shows crosssection SEM pictures of a sample with a 30/120 period heated at $40{ }^{\circ} \mathrm{C} / \mathrm{min}$ up to different temperatures indicated on the corresponding DSC curve [Fig. 8(f)]. In the asprepared sample image [Fig. 8(a)] clear and dark fringes correspond to $\mathrm{Cu}$ and $\mathrm{Mg}$ layers, respectively. Figure 8(b) corresponds to a sample treated up to $210^{\circ} \mathrm{C}$, a midpoint in the vertical growth stage. At this temperature, the intermetallic can be identified as the clear regions that penetrate inhomogeneously into the $\mathrm{Mg}$ layers, probably following the $\mathrm{Mg}$ grain boundaries. ${ }^{9,35}$ The bridge formation of the intermetallic through the $\mathrm{Mg}$ layer initiates the degradation of the multilayer. As temperature rises up, the layered structure gradually vanishes. However, the intermetallic formation and growth do not consume all the reactants and some isolated $\mathrm{Mg}$ regions embedded in the product matrix can be appreciated in the image [Fig. 8(c)]. As temperature increases $\mathrm{Mg}$ segregates into few regions of larger volume, with no apparent contribution to the calorimetric signal. The presence of unreacted $\mathrm{Mg}$ may be due to small deviations from the stoichiometry during the deposition process, as has been obtained by AES (Sec. III B).

\section{DISCUSSION}

\section{A. Nucleation and lateral growth stages}

The determination of the as-deposited film microstructure is the key point to clarify the nature and influence of the interfaces on the nucleation and lateral growth stages. XTEM analysis shows that the growth morphology closely follows the classical zone model, which scales with the respective melting points, or the homologous temperature $\left(T_{s} / T_{m}\right){ }^{36,37}$ Assuming that temperature varies from room temperature to $60{ }^{\circ} \mathrm{C}$ maximum during growth, the homologous temperatures are situated between 0.33 and 0.36 for $\mathrm{Mg}$ and 0.22 and 0.25 for $\mathrm{Cu}$. For the $\mathrm{Mg}$ layers the zone model predicts the development of columnar grains after an initial equiaxial growth which corresponds to zone II. On the contrary, for $\mathrm{Cu}$ a zone $T$ layer morphology which corresponds to an equiaxed microstructure is expected. The specific microstructure of the layer determines the density of grain boundaries, giving a significant difference between the $\mathrm{Mg}$ on the $\mathrm{Cu}$ interface and the $\mathrm{Cu}$ on the $\mathrm{Mg}$ interface as can be observed in the XTEM micrograph (Fig. 4). At $\mathrm{Cu} / \mathrm{Mg}$ interfaces, the grain boundaries at the $\mathrm{Mg}$ layer side are perpendicular to the interface and extend through most of the $\mathrm{Mg}$ film, while at the $\mathrm{Mg}$ side of the $\mathrm{Mg} / \mathrm{Cu}$ interfaces the density of grain boundaries is higher with a smaller penetration distance into the $\mathrm{Mg}$ film. On the other hand, $\mathrm{Cu}$ layers present a similar grain boundary distribution at both sides of the layer due to their polycrystalline equiaxed microstructure. Grain boundaries are the main path for the initial mixing of the reactant species and therefore play an important role in the nucleation process at low temperature, since bulk interdiffusion is almost suppressed. The asymmetry in the grain boundary distribution at each type of interface determines the changes in the interdiffusion region, as has been observed by AES (see Fig. 3). The required concentration profile for nucleation is easily reached at the $\mathrm{Mg} / \mathrm{Cu}$ interfaces, due to the presence of a higher density of grain boundaries, while at the $\mathrm{Cu} / \mathrm{Mg}$ interfaces the presence of perpendicular grain boundaries which are further apart delays the formation of a homogeneous interdiffusion zone, and on the average nucleation starts at slightly higher temperatures as confirmed by calorimetry. Once nucleation has started, new nuclei open diffusion paths that promote the lateral growth process. When coalescence between crystalline grains of the intermetallic phase is completed the lateral growth process stops. While transformation readily takes place at $\mathrm{Mg} / \mathrm{Cu}$ interfaces, the homogeneous interdiffusion zone is achieved at $\mathrm{Cu} / \mathrm{Mg}$ interfaces, and nucleation starts at triple points.

Figure 7 shows the HRTEM of the 20/80 nm sample after the nucleation and lateral growth stages. Two features are worth mentioning. (i) The thickness of the $\mathrm{CuMg}_{2}$ layer is asymmetric at both interfaces. This result is also confirmed by RBS analysis. Whereas at the $\mathrm{Cu} / \mathrm{Mg}$ interface the intermetallic $\mathrm{CuMg}_{2}$ layer is thinner, smoother, and closely parallel to the interface, at the other interface the average thickness is higher and $\mathrm{CuMg}_{2}$ grains penetrate into the $\mathrm{Mg}$ layer at specific locations, probably related to the presence of per- 
a)

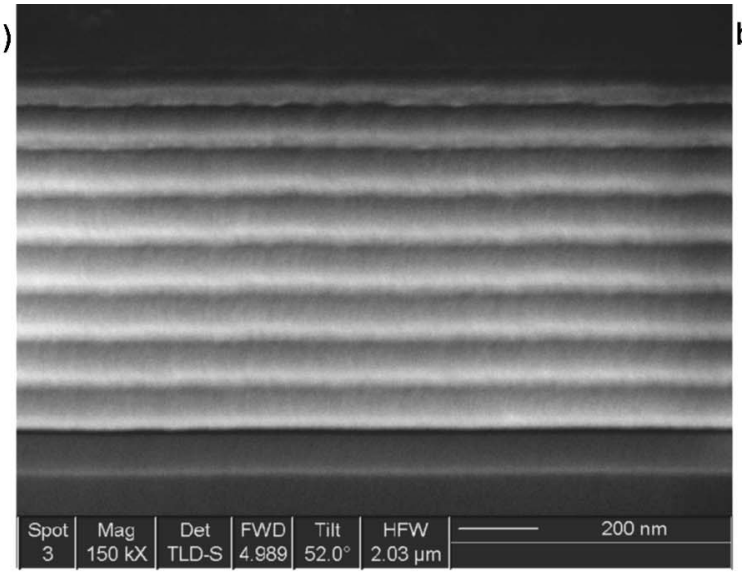

c)

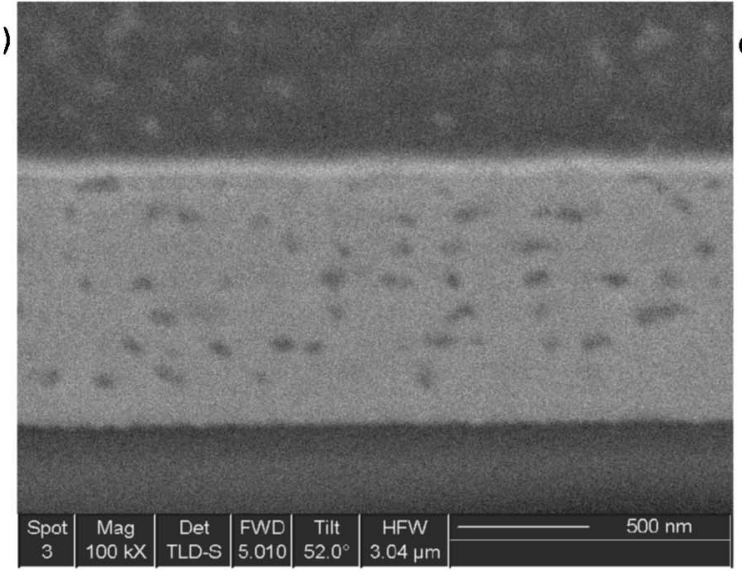

e)

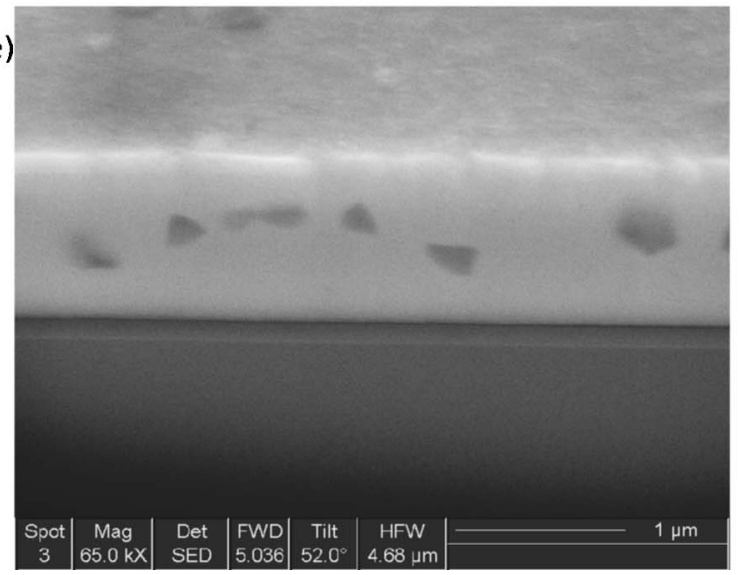

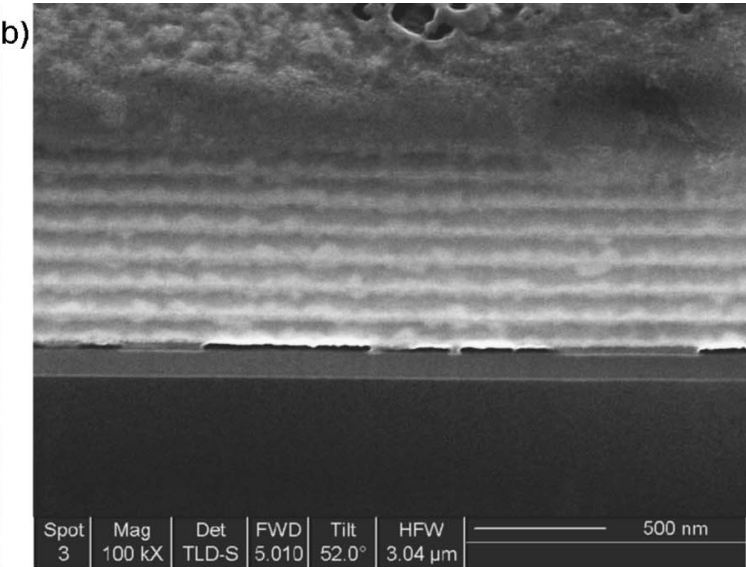

d)

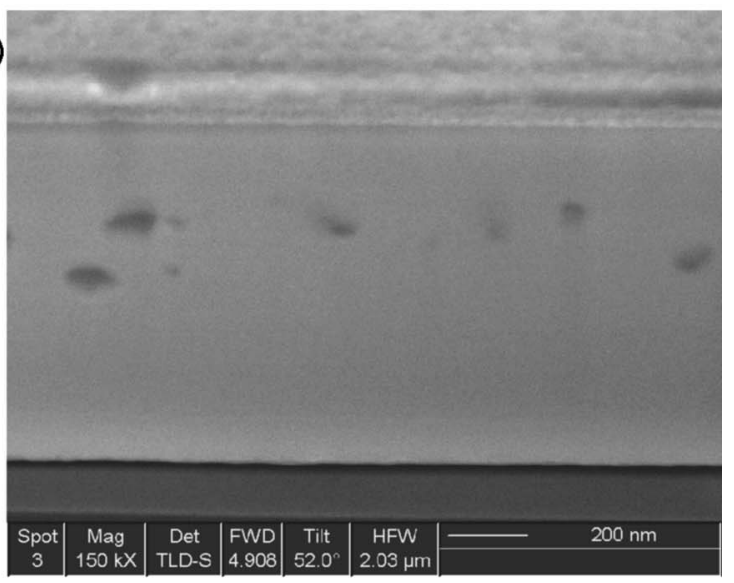

f)

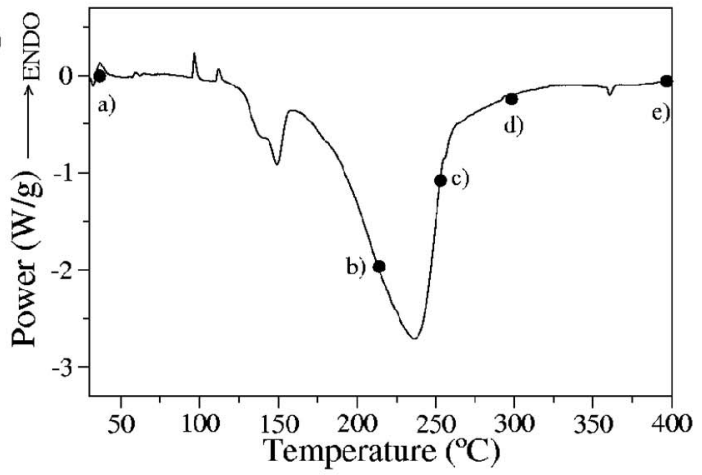

FIG. 8. Cross-section SEM images of the 30/120 sample after different heat treatments: (a) as prepared, (b) up to $210{ }^{\circ} \mathrm{C}$ (middle point of the vertical growth stage), (c) up to $255^{\circ} \mathrm{C}$ (last part of the vertical growth stage), (d) up to $300{ }^{\circ} \mathrm{C}$ (vertical growth stage completed), (e) up to $390{ }^{\circ} \mathrm{C}$, and (f) calorimetric trace of sample $30 / 120$ at $40{ }^{\circ} \mathrm{C} / \mathrm{min}$ where the different heat treatments have been indicated.

pendicular grain boundaries. (ii) $\mathrm{Cu}$ atoms penetrate deeper into the $\mathrm{Mg}$ grain boundaries with some intermetallic $\mathrm{CuMg}_{2}$ growing inside the Mg films.

The number of new nuclei at each interface (see Table II) also agrees qualitatively with this picture. Different microstructures at the top and bottom of the $\mathrm{Mg}$ layer are the causes of the observed double peak in the calorimetric traces. For the samples showing the two overlapped exothermic peaks associated to the nucleation and lateral growth stages the nuclei density is consistently higher at the $\mathrm{Mg}$ on the $\mathrm{Cu}$ interface than at the $\mathrm{Cu}$ on the $\mathrm{Mg}$ interface. The complete process is schematically represented in Fig. 9.
If the changes in the microstructure of the layers influence the nucleation and lateral growth stages, an increase in the period of the multilayers $(L)$ should modify the calorimetric traces. This behavior is observed in Fig. 1 with a transition from one peak at small modulation thickness to a double overlapped peak for higher values. When $L$ increases from 25 to $150 \mathrm{~nm}$ the position of peak 2 moves by $10 \mathrm{~K}$ whereas the position of peak 1 remains unaffected. A previous work by the authors had unambiguously assigned peak 1 to the nucleation and lateral growth stages at the $\mathrm{Mg} / \mathrm{Cu}$ interface, while peak 2 was related to the $\mathrm{Cu} / \mathrm{Mg}$ interface. ${ }^{30}$ In fact, analyzing in more detail Fig. 1 the parameter that 
1)

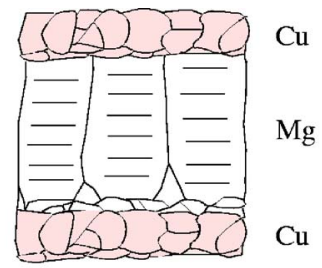

2)

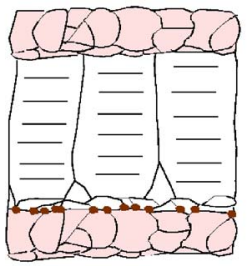

4)

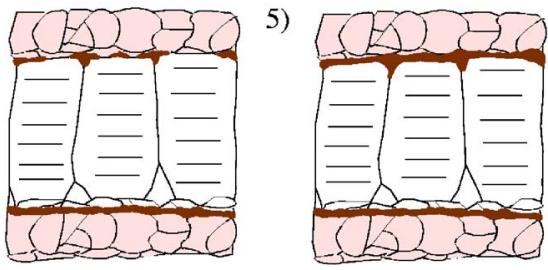

3)

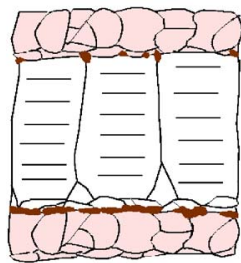

FIG. 9. Schematic representation of the nucleation and lateral growth processes at each kind of interface: (1) as-prepared sample, (2) nucleation at $\mathrm{Mg} / \mathrm{Cu}$ interface, (3) nucleation at $\mathrm{Cu} / \mathrm{Mg}$ interface and lateral growth at $\mathrm{Mg} / \mathrm{Cu}$ interface, (4) lateral growth at $\mathrm{Cu} / \mathrm{Mg}$ interface, and (5) lateral growth process completed at both interfaces.

drives the position of the second peak is the thickness of the $\mathrm{Mg}$ layer. In other systems, such as $\mathrm{Al} / \mathrm{Ni},{ }^{11}$ a similar change in the period of the multilayer is accompanied by a temperature shift of the peak associated to the first stage by $80 \mathrm{~K}$. This behavior has been attributed to an increase of the nuclei density by two orders of magnitude. For the $\mathrm{Cu} / \mathrm{Mg}$ interface, the effect is much lower, $10 \mathrm{~K}$, and the change in nuclei density with $\mathrm{Mg}$ thickness is not easily deduced from the data presented in Table II. However, it is reasonable to argue that a decrease of the $\mathrm{Mg}$ layer thickness will result in a decrease of the grain diameter and therefore a slight increase of the grain boundary density responsible for nucleation. Although no direct TEM observations were performed on films with different thicknesses, the number of grain boundaries should scale with the thickness of the film..$^{9}$ On the contrary, no dependence of the calorimetric traces with changes in the $\mathrm{Cu}$ thickness has been observed. According to the structure zone model, ${ }^{36,37}$ the same microstructure is expected for $\mathrm{Cu}$ in the range of thicknesses explored.

A factor that cannot be neglected is the possible influence of impurities, mainly oxygen or water vapor, in the interfacial reaction. This is specially relevant in this study since $\mathrm{Mg}$ oxidizes to form a $\mathrm{MgO}$ monolayer after a few seconds at $10^{-7}$ Torr. Even $\mathrm{Cu}$ grains can form an oxide monolayer under these partial pressures. Moreover, the absence of oxygen in the AES and RBS measurements does not necessarily mean that oxygen is not present, since these techniques are not sensitive enough for oxygen detection at the trace level. On the other hand, contaminants present at the grain boundaries are known to slow down grain growth. Whether this effect is important or not in the final microstructure of the layers remains to be clarified. It is also known that the presence of an impurity layer at an interface can partially or completely block the interfacial reaction. In order to investigate the possible influence of oxygen in the nucleation process at the $\mathrm{Cu} / \mathrm{Mg}$ interface several experiments were conducted keeping the $\mathrm{Cu}$ and $\mathrm{Mg}$ sources on during the evaporation. Switching from one material to the other was achieved by moving a shutter. This procedure ensures a cleaner interface without interruption of the evaporation. The calorimetric traces of samples grown with and without interruption between $\mathrm{Mg}$ and $\mathrm{Cu}$ presented the double nucleation peak in both cases, therefore the presence of traces of oxygen at the interface does not significantly affect the nucleation rate at the $\mathrm{Cu}$ on the $\mathrm{Mg}$ interface.

\section{B. Vertical growth stage}

Vertical growth starts with the diffusion of both species across the intermetallic layer. ${ }^{14}$ The evolution of the multilayer morphology at different temperatures during and after vertical growth is shown in Fig. 8. The growth front is clearly not plane parallel, since the intermetallic phase grows preferentially along the grain boundaries due to a faster diffusion in these regions. As the film grows the interfaces become rougher and $\mathrm{CuMg}_{2}$ bridges of different widths can be observed. As shown in the SEM micrographs (Fig. 8), excess $\mathrm{Mg}$ atoms segregate into $\mathrm{Mg}$ clusters that grow upon annealing at higher temperatures. The final microstructure depends heavily on the stoichiometry. For 1:2 $\mathrm{Cu}: \mathrm{Mg}$ ratios, a dense and homogeneous $\mathrm{CuMg}_{2}$ layer forms. For excess $\mathrm{Cu}$ atoms a mixture of $\mathrm{CuMg}_{2}$ and $\mathrm{Cu}_{2} \mathrm{Mg}$ phases of variable amount depending on the stoichiometry is observed.

\section{CONCLUSIONS}

The use of complementary techniques, such as RBS, AES, XTEM, and calorimetry, has provided supporting evidence to understand the origin of the differentiated nucleation behavior of $\mathrm{CuMg}_{2}$ at the $\mathrm{Mg} / \mathrm{Cu}$ and $\mathrm{Cu} / \mathrm{Mg}$ interfaces. XTEM observations showed that the microstructure of the as-deposited $\mathrm{Mg}$ layer changes from a region with a high density of grain boundaries during the early growth at the $\mathrm{Mg} / \mathrm{Cu}$ interface to a columnar growth with a lower density of grain boundaries at the $\mathrm{Cu} / \mathrm{Mg}$ interface. The different microstructures at the top and bottom of the $\mathrm{Mg}$ layers are responsible for the observed double peak in the calorimetric traces and play a decisive role in the morphology of the $\mathrm{CuMg}_{2}$ layer after the nucleation and lateral growth stages. The AES and RBS analyses as well as the influence of the $\mathrm{Mg}$ thickness on the shape of the calorimetric traces support this interpretation.

\section{ACKNOWLEDGMENTS}

The financial support by Project No. MAT2004-04761 granted by the Spanish Ministry of Education and 2005SGR00201 granted by the Direcció General de Recerca of the Generalitat of Catalonia is acknowledged. One of the authors (J.L.L.) acknowledges the financial support from the Hungarian National Science Fund (OTKA043437).

${ }^{1}$ P. Gas, J. Lábár, G. Clugnet, A. Kovacs, C. Bergman, and P. Barna, J. Appl. Phys. 90, 3899 (2001). 
${ }^{2}$ F. Nemouchi, D. Mangelinck, C. Bergman, P. Gas, and U. Smith, Appl. Phys. Lett. 86, 041903 (2005).

${ }^{3}$ E. Emeric, P. Gas, G. Clugnet, and C. Bergman, Microelectron. Eng. 50, 285 (2000).

${ }^{4}$ P. Knauth, A. Charaï, C. Bergman, and P. Gas, J. Appl. Phys. 76, 5195 (1994).

${ }^{5}$ R. R. Chromik, W. K. Neils, and E. J. Cotts, J. Appl. Phys. 86, 4273 (1999).

${ }^{6}$ C. Michaelsen, K. Barmak, and T. P. Weihs, J. Phys. D 30, 3167 (1997)

${ }^{7}$ L. A. Clevenger and C. V. Thompson, J. Appl. Phys. 67, 1325 (1990).

${ }^{8}$ P. Bhattacharya, K. N. Ishihara, and K. Chattopadhyay, Mater. Sci. Eng., A A304-306, 250 (2001).

${ }^{9}$ G. Lucadamo, K. Barmak, D. T. Carpenter, and J. M. Rickman, Acta Mater. 49, 2813 (2001).

${ }^{10}$ K. Barmak, J. M. Rickman, C. Michaelsen, R. A. Ristau, J. Kim, G. A. Lucadamo, D. T. Carpenter, and W. S. Tong, J. Vac. Sci. Technol. A 17, 1950 (1999).

${ }^{11}$ E. Ma, C. V. Thompson, and L. A. Clevenger, J. Appl. Phys. 69, 2211 (1991).

${ }^{12}$ J. Li, J. W. Strane, S. W. Russell, S. Q. Hong, J. W. Mayer, T. K. Marais, C. C. Theron, and R. Pretorius, J. Appl. Phys. 72, 2810 (1992).

${ }^{13}$ Q. Z. Hong and F. M. d'Heurle, J. Appl. Phys. 72, 4036 (1992).

${ }^{14}$ B. Arcot, S. P. Murarka, L. A. Clevenger, Q. Z. Hong, W. Ziegler, and J. M. E. Harper, J. Appl. Phys. 76, 5161 (1994).

${ }^{15}$ C. Michaelsen and K. Barmak, J. Alloys Compd. 257, 211 (1997).

${ }^{16}$ K. R. Coffey, L. A. Clevenger, K. Barmak, D. A. Rudman, and C. V. Thompson, Appl. Phys. Lett. 55, 852 (1989).

${ }^{17}$ K. R. Coffey, K. Barmak, D. A. Rudman, and S. Foner, J. Appl. Phys. 72, 1341 (1992).

${ }^{18}$ J. E. E. Baglin, F. M. d'Heurle, and W. N. Hammer, J. Appl. Phys. 50, 266 (1979).
${ }^{19}$ L. A. Clevenger, C. V. Thompson, R. Avilez, and E. Ma, J. Vac. Sci. Technol. A 8, 1566 (1990).

${ }^{20}$ K. F. Dreyer, W. K. Neils, R. R. Chromik, D. Grosman, and E. J. Cotts, Appl. Phys. Lett. 67, 2795 (1995).

${ }^{21}$ R. Roy and S. K. Sen, J. Mater. Sci. 27, 6098 (1992).

${ }^{22}$ V. Vovk, G. Schmitz, and R. Kirchheim, Phys. Rev. B 69, 104102 (2004).

${ }^{23}$ A. M. Gusak, F. Hodaj, and A. O. Bogatyrev, J. Phys.: Condens. Matter 13, 2767 (2001)

${ }^{24}$ R. Bormann, Mater. Res. Soc. Symp. Proc. 343, 169 (1994).

${ }^{25}$ E. Ma, L. A. Clevenger, and C. V. Thompson, J. Mater. Res. 7, 1350 (1992).

${ }^{26}$ M. Seibt, S. Buschbaum, U. Gnauert, W. Schröter, and D. Oelgeschläger, Phys. Rev. Lett. 80, 774 (1998).

${ }^{27}$ R. F. Lever, J. K. Howard, W. K. Chu, and P. J. Smith, J. Vac. Sci. Technol. 14, 158 (1977)

${ }^{28}$ L. A. Clevenger, C. V. Thompson, R. C. Cammarata, and K. N. Tu, Appl. Phys. Lett. 52, 795 (1988).

${ }^{29}$ G. Lucenko and A. Gusak, Microelectron. Eng. 70, 529 (2003).

${ }^{30}$ M. Gonzalez-Silveira, M. T. Clavaguera-Mora, F. Pi, and J. RodriguezViejo, Phys. Rev. B 69, 113411 (2004).

${ }^{31}$ J. Rodríguez-Viejo, M. Gonzalez-Silveira, and M. T. Clavaguera-Mora, J. Appl. Phys. 93, 4447 (2003).

${ }^{32}$ M. Mayer, Nucl. Instrum. Methods Phys. Res. B 194, 177 (2002).

${ }^{33}$ H. E. Kissinger, Anal. Chem. 29, 1702 (1957).

${ }^{34}$ O. Piot, A. Malaurie, and J. Machet, Thin Solid Films 293, 124 (1997).

${ }^{35}$ K. J. Blobaum, D. Heerden, A. J. Gavens, and T. P. Weihs, Acta Mater. 51, 3871 (2003).

${ }^{36}$ J. A. Thorton, Annu. Rev. Mater. Sci. 7, 239 (1977).

${ }^{37}$ H. T. G. Hentzell, C. R. M. Grovenor, and D. A. Smith, J. Vac. Sci. Technol. A 2, 218 (1984). 